\title{
Relative sensitivity of DNA and photosystem II in Ulva intestinalis (Chlorophyta) under natural solar irradiation
}

\author{
Frauke Pescheck*, Hanna Campen, Lars Nichelmann, Wolfgang Bilger \\ Botanical Institute, Christian-Albrechts-University Kiel, Olshausenstr. 40, 24098 Kiel, Germany
}

\begin{abstract}
High intensities of sunlight can result in DNA and photosystem II (PSII) damage. However, the relative sensitivity of both these targets under natural sunlight and especially over a long period has not been studied in algae so far. Although DNA damage is highly specifically induced by ultraviolet-B radiation (UVB, $280-315 \mathrm{~nm}$ ), PSII is inactivated by a broad spectrum. The green macroalga Ulva intestinalis is an appropriate and interesting study organism with which to investigate the relative importance of the 2 different targets of sunlight because this alga contains no UV-screening protective pigments, although it is exposed to strong solar irradiation in its natural habitat. This entails a high risk of DNA damage. Therefore, diel time courses and long-term development of DNA damage and the optimal quantum yield of PSII $\left(F_{\mathrm{v}} / F_{\mathrm{m}}\right)$ were studied in situ. $F_{\mathrm{v}} / F_{\mathrm{m}}$ was extremely reduced at noon, but a fast recovery was observed in the afternoon. As dark-adapted basal fluorescence $\left(F_{0}\right)$ of PSII was substantially decreased during the day, non-photochemical quenching is suggested to be a key photoprotective strategy in $U$. intestinalis. In contrast, even in samples with strongly reduced $F_{\mathrm{v}} / F_{\mathrm{m}}$, only very low DNA damage was found, irrespective of the accumulated UVB dose. We propose that efficient photoreactivation driven by natural sunlight balances the induction of dimers. This leads to a higher UVB tolerance of DNA than that observed in algae under experimental UVB irradition. In this field study, $U$. intestinalis suffered more from photoinhibition than from DNA damage.
\end{abstract}

KEY WORDS: Diel cycle $\cdot$ DNA damage $\cdot$ Intertidal zone $\cdot$ Long-term data $\cdot$ Photosynthetic efficiency $\cdot$ Ultraviolet radiation $\cdot$ Sunlight $\cdot$ Ulva intestinalis

\section{INTRODUCTION}

A functional photosynthetic apparatus and intact DNA are essential for the growth of plants. Although phototrophs depend on light, the 2 very important processes photosynthesis and DNA expression are sensitive to damage by sunlight (Peak \& Peak 1983, Teramura \& Sullivan 1994, Jansen \& Bornman 2012, Vass 2012). Photodamage to DNA is mainly generated by ultraviolet-B (UVB, 280-315 nm) radiation (Cadet et al. 2012), creating covalent bonds between 2 neighboring cytosine or thymine bases. The majority of resulting dimers are cyclobutane-pyrimidine dimers (CPDs) (Setlow \& Carrier 1966, Mitchell \& Nairn 1989,
Douki et al. 2000). A single dimer may completely stop the progression of DNA and RNA polymerases and thereby inhibit replication and gene expression (Sauerbier et al. 1970). However, photoreactivation can efficiently repair such UVB-induced DNA lesions. This photocatalytic splitting of the dimers is empowered by blue light and UVA radiation carried out by a specific enzyme, the photolyase (Britt 1996, Sancar 2003). This means that UVB-induced damage and UVA-driven repair occur simultaneously in sunlight, demonstrating that it is very important to evaluate the influence of solar radiation on the DNA integrity of an organism under the polychromatic composition of sunlight (Bray \& West 2005, Caldwell et al. 2007). 
The action spectrum for inhibition of photosynthesis peaks in the UV region but extends far into the visible range (Takahashi et al. 2010). Destruction of the water splitting apparatus of photosystem II (PSII) can be one of the starting points of photoinactivation (Vass et al. 1996, Hakala et al. 2005). Damage to this protein complex can be explained by the direct absorption of UVB and UVA radiation (Ohnishi et al. 2005). In the absence of water splitting, absorption of photosynthetically active radiation (400-700 nm, PAR) by photosynthetic pigments leads to the accumulation of positively charged $\mathrm{P} 60^{+}$radicals and the subsequent oxidation of components of PSII. In addition, the high photon flux densities (PFD) of sunlight can also lead to excessive and therefore potentially harmful irradiation as soon as an imbalance of light and dark reactions of photosynthesis set in. In this situation, an uncontrolled transfer of excited electrons to oxygen might occur. It has been shown conclusively that UVB and UVA radiation as well as PAR can induce the formation of reactive oxygen species (ROS) in chloroplasts (Snyrychova et al. 2007). One of the central proteins of PSII, the D1 protein, and especially its turnover are the major targets of these radicals (Jegerschöld et al. 1990, Nishiyama et al. 2001). Thus, although sunlight-induced inactivation of PSII cannot easily be ascribed to a specific proportion of the solar spectrum, it may be quite a sensitive indicator of the presence of light stress.

UV and high PAR tolerance of PSII is mainly attributed to an active repair cycle of PSII (Nishiyama et al. 2001, Allakhverdiev \& Murata 2004). The function of this repair cycle can be protected by antioxidative substances and enzymes in the chloroplast against an inhibition by ROS (Nishiyama et al. 2001, HakalaYatkin et al. 2011). Similarly, non-photochemical quenching (NPQ) lowers the production of ROS by quenching of absorbed energy via efficient heat dissipation (Müller et al. 2001, Jahns \& Holzwarth 2012). This way the quantum yield of PSII is reduced as in photoinactivation, but in a controlled and regulated photoprotective manner (Osmond et al. 1993).

Besides the acute effects of high irradiances and UVB radiation, on longer time scales, other aspects, such as acclimation and accumulation of damage as a result of the balance between induction and repair, have to be considered (Jansen et al. 1998, Allakhverdiev \& Murata 2004). Long-term monitoring under natural solar irradiation is necessary to reveal the ecological relevance of light-induced damage. Up to now, only a few long-term studies of photosynthetic efficiency in plants or algae have been conducted in the field (Valladares \& Pearcy 1997, Altamirano et al.
2000, Bischof et al. 2002, Michler et al. 2002). As regards DNA damage, long-term field observations are much rarer still, as well as sometimes being contradictory. Whereas a positive correlation of increased DNA damage with increased UVB irradiances due to ozone variations was observed in a herbaceous plant, Gunnera magellanica, in south Argentina, and in 3 Antarctic mosses (Rousseaux et al. 1999, Turnbull \& Robinson 2009), no long-term accumulation of CPDs was found in Arctic tundra plants even under supplemental UVB conditions (Rozema et al. 2006). In picoplankton from mid-latitudes, an increase in DNA damage after noon was reported (Buma et al. 2001). However, in that study, DNA damage was not followed over complete diel courses or longer periods. These results demonstrate the lack of knowledge about long-term effects of UVB on DNA in photosynthetic organisms and especially in macroalgae.

The organism of the present study, Ulva intestinalis L., is one of the most dominant green macroalgal species in the intertidal zone (Sousa 1979, Nelson et al. 2003, Wang et al. 2012) and the genus Ulva has gained a lot of interest as a model organism (Wichard et al. 2015). Ulva intestinalis establishes dense populations in the upper eulittoral zone, where emergence and concomitant exposure to unattenuated solar radiation regularly occur. In addition, because of its tubular morphology (Koeman \& van den Hoek 1982), the gas-filled thalli often float on the water surface so that times of emergence can be extended. In this habitat, resistance to strong solar irradiance is obviously a prerequisite for survival. From shortterm stress experiments, Ulva is well known to be highly tolerant to large variations in salinity (Reed \& Russell 1979) and temperature (Henley et al. 1992). Whereas in these short-term experiments Ulva species also proved to be very tolerant towards light stress (Franklin et al. 1992, Henley et al. 1992, Figueroa et al. 2003, Gómez et al. 2004), in another study $U$. aff. rotundata showed strong UVBenhanced bleaching after exposure to full sunlight for $3 \mathrm{~d}$ (Bischof et al. 2002). Furthermore, investigations of UVB-induced DNA damage in macroalgae are scarce and most of these results have been gained from short-term laboratory studies (van de Poll et al. 2001, Roleda et al. 2006, Pescheck et al. 2014). The analysis of DNA damage in U. intestinalis is even more interesting as this species lacks UVB protective pigments, which are a major defense against UVB-induced damage in higher plants (Bornman et al. 1997). Hence, it seems important to investigate the high light tolerance of Ulva under long-term solar irradiation and to search for sensitive 
structures. Therefore, we studied the effect of natural sunlight on CPD formation in the DNA, on short-term as well as on long-term scales in $U$. intestinalis in comparison to photochemical efficiency of PSII. We hypothesized that $U$. intestinalis accumulates CPD depending on the solar UVB dose because of the lack of UVB protective pigments. We further hypothesized that the proportion of DNA and PSII damage under solar irradiation would be different from that observed in a laboratory study (Pescheck et al. 2014). The additional spectral components in sunlight may either mitigate or exacerbate the effects of UVB on both photosensitive structures.

\section{MATERIALS AND METHODS}

\section{Field experiments}

From May 2009 to September 2013, 6 short-term field studies with Ulva intestinalis were conducted (Table 1). The optimal quantum yield of PSII $\left(F_{\mathrm{v}} / F_{\mathrm{m}}\right)$ and the concentration of CPDs in the DNA were analyzed over diel time courses. Additionally, UVB screening was determined for a subsample of the analyzed populations. The short-term investigations took place at different locations at the shore of the Baltic Sea around Kiel, Germany (Table 1). On the beaches of Meierwik, Dänisch-Nienhof (abbreviated as D.Nienhof) and Surendorf, dense populations of $U$. intestinalis grow on small boulders from April to November. A long-term study site was established close to one of the locks on the Kiel Canal in Kiel Holtenau (hereafter referred to as the Lock, whereby
Locks I, II, III refer to 3 different measuring days). An experimental setup with open boxes was installed in which the algae could grow and be observed for several weeks under natural light, temperature and salinity conditions. For this experiment, stones (diameter ca. $15 \mathrm{~cm}$ ) densely overgrown with thalli of $U$. intestinalis were collected in Surendorf and transferred to the Lock in buckets filled with seawater. There, the stones with the algae were placed in floating plastic boxes (SN 106601, 600 × $400 \times 400 \mathrm{~mm}$, Schoeller Allibert) with a $1 \times 1 \mathrm{~cm}$ grid of holes on all sides to allow water exchange with the fjord. Inside the boxes, the stones were kept in position by holes that were cut into a custom-made PVC floor. The height of this floor was adjusted so that most of the algae reached the water surface and floated horizontally as a result of the gas-filled thalli segments. The boxes were kept buoyant with the help of 2 connected air-filled plastic pipes $(1 \mathrm{~m} \times 15 \mathrm{~cm})$. Four boxes were tied to the north side of 1 fender in the entrance to 1 of the 4 lock chambers on the fjord side. This experiment was repeated with freshly collected algae (Expt A from 28 June to 24 July 2013, Expt B from 25 July to 16 August 2013). During both runs, the boxes were repeatedly cleaned of epibionts (e. $g$. barnacles, diatoms, green microalgae) with a scrubbing brush. Sometimes epiphytes accumulated on $U$. intestinalis and were removed by carefully washing the algae in the open water at night. The boxes floated in a water area that was enclosed by fenders such that the water surface was very calm. The resulting stable exposure of the upper layer of thalli rarely occurs under natural conditions, but was also observed during the measurements in

Table 1. Overview of the daily courses with location, date, daily accumulated photosynthetically active radiation (PAR) and biologically effective $\mathrm{UVB}_{\mathrm{BE}}(280-315 \mathrm{~nm}$ ) dose (weighted after Ghetti et al. 1999), maximal photon flux density (PFD) and UVB irradiance, mean water temperature $\left(T_{\text {water }}\right)$, measurement interval and number of replicates for optimal quantum yield $\left(F_{\mathrm{v}} / F_{\mathrm{m}}\right)$ and DNA damage (cyclobutane-pyrimidine dimers, CPDs), and UVB transmittance ( $\left.T_{\mathrm{UVB}}, \pm \mathrm{SD}\right)$ of macrothalli. nd: no data

\begin{tabular}{|c|c|c|c|c|c|c|c|c|}
\hline $\begin{array}{l}\text { Dänisch-Nienhof } \\
\left(54^{\circ} 28^{\prime} 51^{\prime \prime} \text { N, } 10^{\circ} 8^{\prime} 8^{\prime \prime} \text { E) }\right.\end{array}$ & $16 \mathrm{Jul} 2010$ & 58.3 & 5.03 & 1682 & 0.67 & 20 & $\begin{array}{c}\text { 04:30-20:30, } F_{\mathrm{v}} / F_{\mathrm{m}} \\
\text { every } 2 \mathrm{~h}, \mathrm{CPDs} \text { every } 4 \mathrm{~h} \text {, } \\
\mathrm{n}=8\end{array}$ & $96 \pm 8$ \\
\hline $\begin{array}{l}\text { Surendorf } \\
\left(54^{\circ} 28^{\prime} 51^{\prime \prime} \mathrm{N}, 10^{\circ} 5^{\prime} 10^{\prime \prime} \mathrm{E}\right)\end{array}$ & 24 Jul 2012 & 48.7 & 4.60 & 1477 & 0.64 & 21 & $\begin{array}{c}\text { 04:00-04:00, } F_{\mathrm{v}} / F_{\mathrm{m}} \\
\text { every } 2 \mathrm{~h}, \mathrm{CPDs} \text { every } 4 \mathrm{~h} \text {, } \\
\mathrm{n}=5\end{array}$ & $79 \pm 3$ \\
\hline Lock Kiel-Holtenau & 12 Jul 2013 & 56.8 & 5.60 & 1724 & 0.76 & 20 & 00:00-00:00, $F_{\mathrm{v}} / F_{\mathrm{m}}$ & nd \\
\hline$\left(54^{\circ} 22^{\prime} 7^{\prime \prime} \mathrm{N}, 10^{\circ} 8^{\prime} 43^{\prime \prime} \mathrm{E}\right)$ & $23 \mathrm{Jul} 2013$ & 58.2 & 5.79 & 1715 & 0.78 & 22 & every $2 \mathrm{~h}$, CPDs every $4 \mathrm{~h}$, & nd \\
\hline & 6 Aug 2013 & 42.5 & 4.37 & 1592 & 0.68 & 20 & $\mathrm{n}=4$ & $79 \pm 11$ \\
\hline
\end{tabular}


Surendorf when exceptionally calm weather conditions prevailed.

\section{Environmental data}

In Meierwik and at the Lock in Holtenau, a data logger (CR 1000, Campbell Scientific) was installed that recorded several environmental parameters. The water temperature was measured with a resistance thermometer PT100 in Meierwik or with a temperature probe (107-L, Campbell Scientific) $3 \mathrm{~cm}$ below the water surface at the Lock. Approximately $2 \mathrm{~m}$ above the water surface, UVB and visible radiation were registered with a UVB-sensitive photodiode (in Meierwik: GUVB-T10GD, Roithner Lasertechnik; at the Lock: Tocon E + diffusor, sglux SolGel Technologies) and a photodiode (G1118, Hamamatsu Photonics), respectively. The diodes were incorporated into custom-made housings constructed for cosine-corrected measurements. During the field measurements in D.Nienhof and Surendorf, the UVB radiation was measured with a hand-held custom-made UVB sensor (Veit et al. 1996) connected to a voltmeter approximately $1.5 \mathrm{~m}$ above the water surface. Photon flux density (PFD, 400-700 nm) was measured using a LICOR quantum sensor (LI-190), and water temperature with a standard thermometer. All radiation sensors were calibrated against a double monochromator spectroradiometer (DM 150, Bentham Instruments) and the UVB signals were converted into $\mathrm{W} \mathrm{m}^{-2} \mathrm{UVB}$ irradiance. To calculate the biologically effective UVB $\left(\mathrm{UVB}_{\mathrm{BE}}\right)$, the UVB irradiance was further weighted with the function of Ghetti et al. (1999) using a correlation factor for unweighted to weighted irradiance from a solar spectrum recorded in April 2009 in Kiel with the same spectroradiometer.

\section{Measurements of chlorophyll fluorescence}

For all measurements, the upper 4 to $6 \mathrm{~cm}$ of green thalli floating on the water were collected. The upper $2 \mathrm{~cm}$ of these pieces were immediately placed in $2 \mathrm{ml}$ reaction tubes and frozen in liquid nitrogen for subsequent DNA extraction. The remains of the same thalli were used for the determination of the optimal quantum yield of PSII so that it was possible to pair the $F_{\mathrm{m}} / F_{\mathrm{m}}$ and CPD data from each individual thallus. The thallus pieces were mounted in leaf clips (Walz) and kept in a water bath at ambient water temperature for dark adaptation for $20 \mathrm{~min}$ (in Surendorf $15 \mathrm{~min}) . F_{\mathrm{o}}$ and $F_{\mathrm{m}}$ levels were then determined using a Mini-PAM fluorometer (Walz) in Meierwik, D. Nienhof and Surendorf or a PAM-2100 fluorometer (Walz) at the Lock. In Surendorf and at the Lock after the first saturating pulse, the thalli were kept in darkness in the leaf clips and the measurement of $F_{\mathrm{o}}$ and $F_{\mathrm{m}}$ was repeated after $1 \mathrm{~h}$ dark adaptation. Afterwards, the fluorescence signal was recorded for each leaf clip with a blue fluorescence standard (Walz). This allowed us to correct the absolute fluorescence values for optical differences among the leaf clips and the temperature dependence of the instruments.

\section{DNA damage detection}

The frozen samples of the upper $2 \mathrm{~cm}$ of the thalli were transported to the laboratory in liquid nitrogen and stored at $-85^{\circ} \mathrm{C}$ until analysis. All procedures for the detection of CPDs per megabase $\left(\mathrm{Mb}^{-1}\right)$ by immuno-dot blotting followed the method described in Pescheck et al. (2014). The reagent for chemiluminescence was Pierce ECL (Thermo Fisher Scientific).

\section{Experimentally-induced CPD formation and reduction of PSII efficiency}

The intrinsic sensitivity of DNA and PSII in $U$. intestinalis towards UVB radiation was determined by laboratory dose-dependency experiments. Fieldcollected algae were cleaned and cultured in Petri dishes with $40 \mathrm{ml}$ nutrient-enriched half-marine sterile filtered seawater. The medium was changed every $2-3 \mathrm{~d}$. The algae were kept in a temperaturecontrolled climate cabinet (Rumed, Rubarth Apparate) at $9^{\circ} \mathrm{C}$, and illumination was from 3 fluorescence tubes (General Electrics) delivering approximately 10-12 $\mu \mathrm{mol}$ photons $\mathrm{m}^{-2} \mathrm{~s}^{-1}$ PAR for $16 \mathrm{~h}$ followed by $8 \mathrm{~h}$ darkness. This pre-experimental culture was maintained for 10-19 d after sampling to ascertain that no UVB-induced damages originating from the field were present in the algae anymore. Five UVB doses were applied by exposure for $1 \mathrm{~h}$ to different fluence rates $\left(0-5 \mathrm{~W} \mathrm{~m}^{-2}\right)$ of UVB irradiance emitted by UVB fluorescence tubes (TL40/12RS, Philips). During the exposure, 2 open Petri dishes per UVB intensity were covered by WG295 glass filters (Schott) to exclude wavelengths under $295 \mathrm{~nm}$. Two Petri dishes with control samples were kept under a UV-blocking plexiglass filter (GS 321, Röhm). From each dish, 4 subsamples were frozen for DNA damage detection immediately after UVB exposure. Afterwards, the dishes were dark incubated for 
20 min and $F_{\mathrm{v}} / F_{\mathrm{m}}$ was determined with an Imaging PAM chlorophyll fluorometer (Walz).

\section{UVB screening}

From the analyzed populations, some thalli were brought to the laboratory directly after the last measurement in the field and used for screening measurements within a maximum of $3 \mathrm{~h}$ after sampling. The thalli were transported in $50 \mathrm{ml}$ tubes filled with water from the sampling site. Basal fluorescence excited with blue-green light (420-550 $\mathrm{nm}$ ) and UVB radiation $\left(\lambda_{\max }=314 \mathrm{~nm}, 18 \mathrm{~nm}\right.$ half bandwidth) was determined with a Xenon PAM fluorometer (Walz) as described in Pescheck et al. (2010). The excitation beam had a pulse rate of $4 \mathrm{~Hz}$. Measuring was applied for $30 \mathrm{~s}$ for each excitation wavelength. Apparent UVB transmittance was calculated as defined in Pescheck et al. (2010).

\section{Data analysis}

Statistics were calculated using SigmaPlot version 11.0 (Systat Software) or GraphPad 5 (GraphPad Software). The diel cycles of $F_{\mathrm{v}} / F_{\mathrm{m}}$ and CPDs $\mathrm{Mb}^{-1}$ were analyzed by one-way repeated measures ANOVA, and if a significant difference was detected the groups were separated with a Tukey post hoc comparison. The data for PSII efficiency from Surendorf and Lock III were not normally distributed and thus were analyzed using Friedman repeated measures ANOVA on ranks. In the long-term study, linear regression analysis was performed of $F_{\mathrm{v}} / F_{\mathrm{m}}$ and accumulated CPDs $\mathrm{Mb}^{-1}$. Additionally, linear regressions were calculated against the daily dose of PFD and $\mathrm{UVB}_{\mathrm{BE}}$ (both integrated until the time point of measurement: 13:00 h). From the light measurements recorded with the data logger, mean values of every 15 min were calculated and integrated over $24 \mathrm{~h}$ for the accumulated doses.

\section{RESULTS}

\section{Environmental data}

Environmental conditions at all sites were generally similar except for 7 May 2009 in Meierwik and

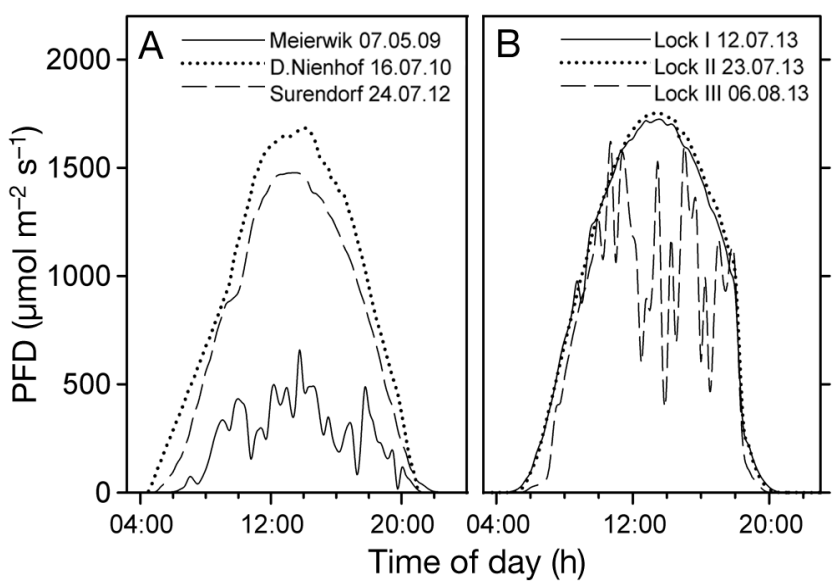

Fig. 1. Diel courses of horizontal photon flux density (PFD) at (A) the 3 beach locations and (B) the Lock in Kiel-Holtenau on 3 measuring days (Lock I, Lock II and Lock III). PFD was measured automatically as 15 min means in Meierwik and at the Lock. In D.Nienhof and Surendorf, PFD was measured approximately every $30 \mathrm{~min}$

Fig. 2. Diel courses of optimal quantum yield of photosystem II $\left(F_{\mathrm{v}} / F_{\mathrm{m}}\right)$. (A) In situ measurements on the 3 beaches; (B) in boxes at the Lock. Data are means $\pm 1 \mathrm{SD}, \mathrm{n} \geq 4$. Notice the different scaling of the time of day in (A) and (B)

6 August 2013 at the Lock (Table 1). Although on 7 May 2009 and 6 August 2013 the sky was overcast, the rest of the days were clear and the irradiance courses resembled sinusoidal curves (Fig. 1). The maximal irradiances of $660-1700 \mu \mathrm{mol}$ photons $\mathrm{m}^{-2}$ $\mathrm{s}^{-1}$ were observed between 13:15 and 14:00 h (CEST) (Table 1).

\section{Short-term observations}

On all days, characteristic diel variations of the optimal quantum yield of PSII following irradiance were found (Fig. 2). The highest values of $F_{\mathrm{v}} / F_{\mathrm{m}}$ were always at night (Meierwik), pre-dawn (D.Nienhof) or 
Table 2. Maximum reduction of optimal quantum yield $\left(F_{\mathrm{v}} / F_{\mathrm{m}}\right)$ and maximum concentration (means $\pm \mathrm{SD}$ ) of cyclobutane-pyrimidine dimers per megabase $\left(\mathrm{CPD} \mathrm{Mb} \mathrm{Mb}^{-1}\right)$ during diel courses. The time of day of the respective observation is given in parentheses (h). ns: not significantly different from all other day times (repeated measures ANOVA); nd: not determined

\begin{tabular}{|lccc|}
\hline Location & Date & $\begin{array}{c}\text { Max. reduction } \\
\text { of } F_{\mathrm{v}} / F_{\mathrm{m}}(\%)\end{array}$ & $\begin{array}{c}\text { Max. CPD } \\
\mathrm{Mb}^{-1}\end{array}$ \\
\hline Meierwik & 7 May 2009 & $8(13: 00)^{\mathrm{ns}}$ & $44 \pm 24(04: 00)^{\mathrm{ns}}$ \\
D.Nienhof & 16 Jul 2010 & $63(13: 00)$ & $44 \pm 38(13: 00)^{\mathrm{ns}}$ \\
Surendorf & 24 Jul 2012 & $56(16: 00)$ & $6 \pm 2(12: 00)^{\mathrm{ns}}$ \\
Lock I & 12 Jul 2013 & $66(12: 00)$ & $40 \pm 35(04: 00)^{\mathrm{ns}}$ \\
Lock II & 23 Jul 2013 & $77(12: 00)$ & $49 \pm 14(14: 00)^{\mathrm{ns}}$ \\
Lock III & 6 Aug 2013 & $55(10: 00)$ & nd \\
\hline
\end{tabular}

in the early morning (Surendorf, Locks I-III, repeated measures ANOVA $\mathrm{p}<0.05$ ). During the afternoon, concomitant with the peak of irradiance, a significant reduction of $F_{\mathrm{v}} / F_{\mathrm{m}}$ occurred between 12:00 and 16:00 h except for 7 May 2009 in Meierwik and 6 August 2013 at the Lock. Maximal reduction of $F_{\mathrm{v}} / F_{\mathrm{m}}$ was $55-77 \%$ (Table 2).

In D.Nienhof, PSII recovery started with a significant increase from 16:00 to 18:00 h. From 20:00 h onwards, the $F_{\mathrm{v}} / F_{\mathrm{m}}$ values were identical to the morning values. Likewise, recovery was completed at 22:00 $\mathrm{h}$ in Surendorf and at Locks I and II. At that time, no statistically significant difference to the maximum $F_{\mathrm{v}} / F_{\mathrm{m}}$ values of the early morning could be found. According to the low irradiance observed in

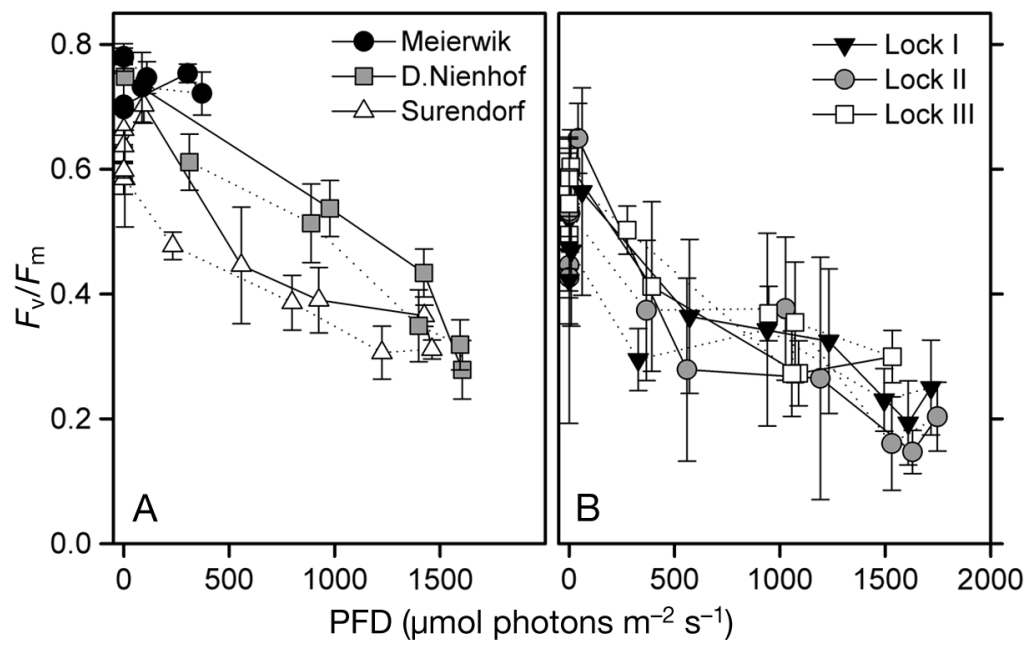

Fig. 3. Relationship of optimal quantum yield of photosystem II $\left(F_{\mathrm{v}} / F_{\mathrm{m}}\right)$ measured after 15 or 20 min dark incubation and incident photon flux density (PFD) during the daily courses from (A) the in situ measurements on the 3 beaches and (B) the boxes at the Lock. Solid lines connect values from increasing PFDs; dotted lines connect values from decreasing PFDs. Data are from Figs. 1 and 2. $F_{\mathrm{v}} / F_{\mathrm{m}}$ data are means $\pm 1 \mathrm{SD}, \mathrm{n} \geq 4$
Meierwik (Fig. 1), $F_{\mathrm{v}} / F_{\mathrm{m}}$ was not significantly reduced throughout the day at this site, except for the late-afternoon value of the previous day (repeated measures ANOVA, $\mathrm{p}<0.05$; Fig. 2A). On Day 3 at the Lock, the weather was cloudier, which is mirrored in the time course in a more variable $F_{\mathrm{v}} / F_{\mathrm{m}}$ (Fig. 2B).

$F_{\mathrm{v}} / F_{\mathrm{m}}$ and the instantaneous photon flux density had a relatively constant relationship during the 6 diel courses (Fig. 3). One can observe a distinct absence of a hysteresis, indicating that the reduction of $F_{\mathrm{v}} / F_{\mathrm{m}}$ during the day may not have been caused by long-lasting damage but by fast reversible downregulation of PSII.

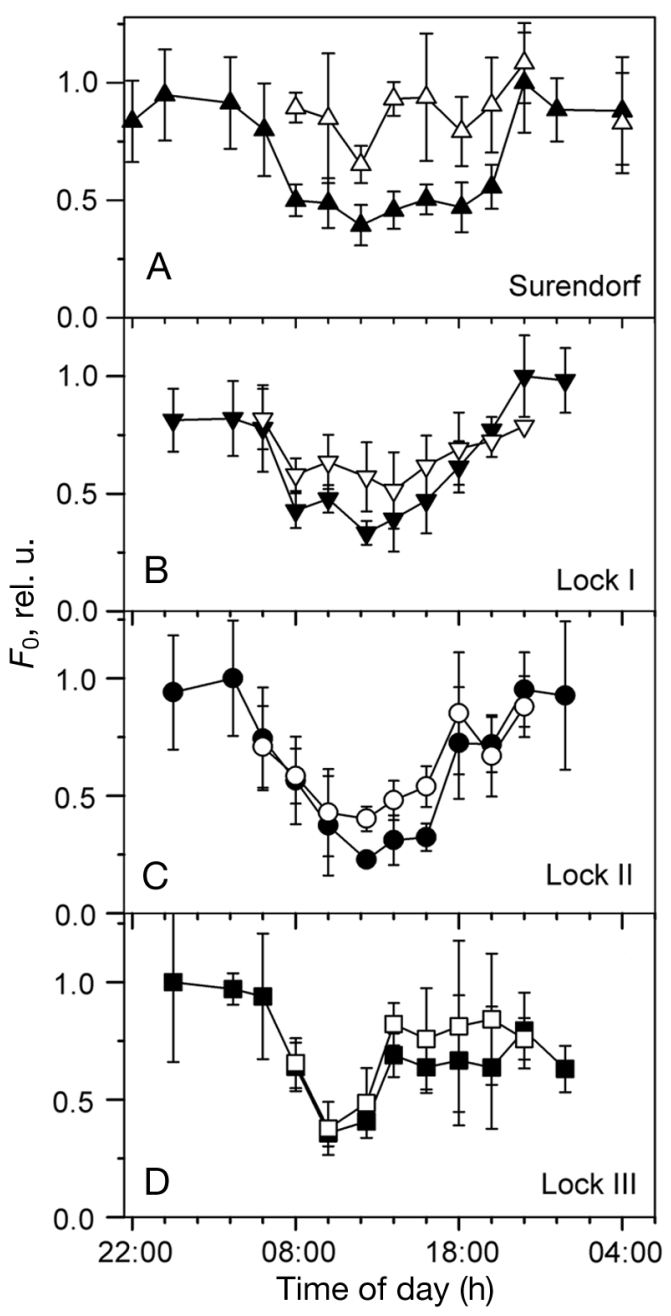

Fig. 4. Normalized basal fluorescence $\left(F_{\mathrm{o}}\right)$ values after 15 or $20 \mathrm{~min}$ (open symbols) and 60 min (closed symbols) darkness during the diel courses in (A) Surendorf and (B-D) at the Lock in Kiel-Holtenau. Relative units of $F_{\mathrm{o}}$ were calculated from the raw data of $F_{0}$ divided by the signal of a blue fluorescence standard, and were normalized to the maximal value during each diel course. Data are means $\pm \mathrm{SD}, \mathrm{n} \geq 4$ 


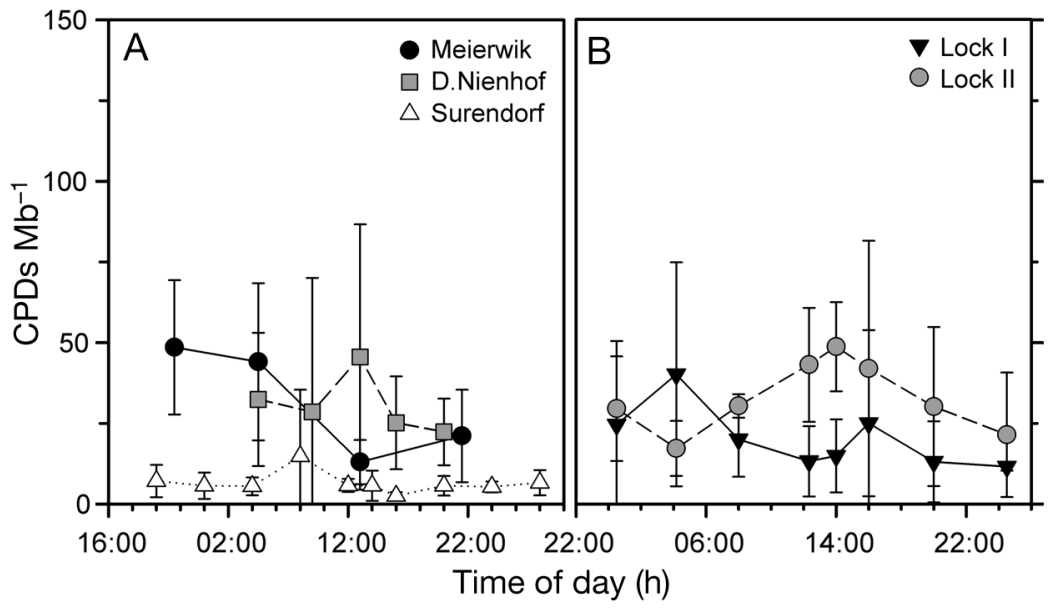

Fig. 5. Concentrations of cyclobutane-pyrimidine dimers per megabase (CPDs $\mathrm{Mb}^{-1}$ ) during the diel courses in U. intestinalis from (A) the in situ measurements at the 3 beach locations and (B) the boxes at the Lock. Data are means $\pm S D, n \geq 4$. Notice the different scaling of the time of day in (A) and (B)

In Surendorf and at the Lock, the diel variation of basal fluorescence $\left(F_{\mathrm{o}}\right)$ was determined after 15 or 20 min and 60 min of dark incubation (Fig. 4). Despite a considerable scatter of the data, a strong decrease of up to $76 \%$ of the normalized $F_{\mathrm{o}}$ signal was apparent during the $4 \mathrm{~d}$. A substantial quenching of $F_{\mathrm{o}}$ was also observed after $1 \mathrm{~h}$ dark incubation at the Lock, but not at Surendorf, indicating a faster reversibility at the latter location. One explanation for these results may be that before the in situ measurements at Surendorf, the

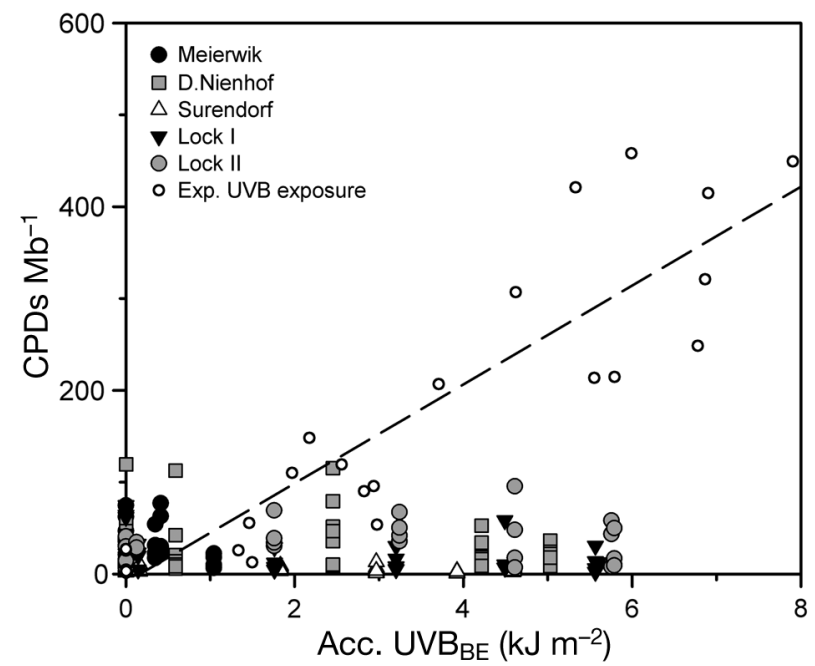

Fig. 6. Concentration of cyclobutane-pyrimidine dimers per megabase (CPDs $\mathrm{Mb}^{-1}$ ) in Ulva intestinalis in relation to accumulated (Acc.) UVB dose. Field CPD data are from Fig. 5. For comparison, the induction of CPDs $\mathrm{Mb}^{-1}$ in $U$. intestinalis exposed to experimental (Exp.) UVB is given (dashed line, $r^{2}=0.83$ ). Laboratory data are mean values of $n=8$ from 6 independent experiments algae had been high light stressed for only $1 \mathrm{~d}$, whereas inside the boxes at the Lock they had been exposed for $2 \mathrm{wk}$.

The concentration of DNA damage did not show a distinct diel pattern in any of the experiments (Fig. 5). No statistically significant differences were detected between times of day (1-way repeated measures ANOVA, p > 0.05; Table 2). There was also no relationship of CPDs $\mathrm{Mb}^{-1}$ with accumulated UVB dose in the field ( $p=0.61$; Fig. 6). For comparison, CPDs induced in Ulva intestinalis under experimental exposure conditions are shown (Fig. 6). The $y$-intercept at 36 CPDs $\mathrm{Mb}^{-1}$ of the regression line of these data was higher than the mean of all fieldmeasured CPD concentrations (28 CPDs $\mathrm{Mb}^{-1}$ ). In the laboratory, the same dose response was observed when the duration, rather than the intensity, of the UVB exposure was varied instead of the intensity (data not shown). This revealed time-dose reciprocity in CPD formation under experimental UVB exposure.

\section{Relative sensitivity of DNA and PSII}

In situ CPD formation did not increase with decreasing PSII quantum yield determined with paral-

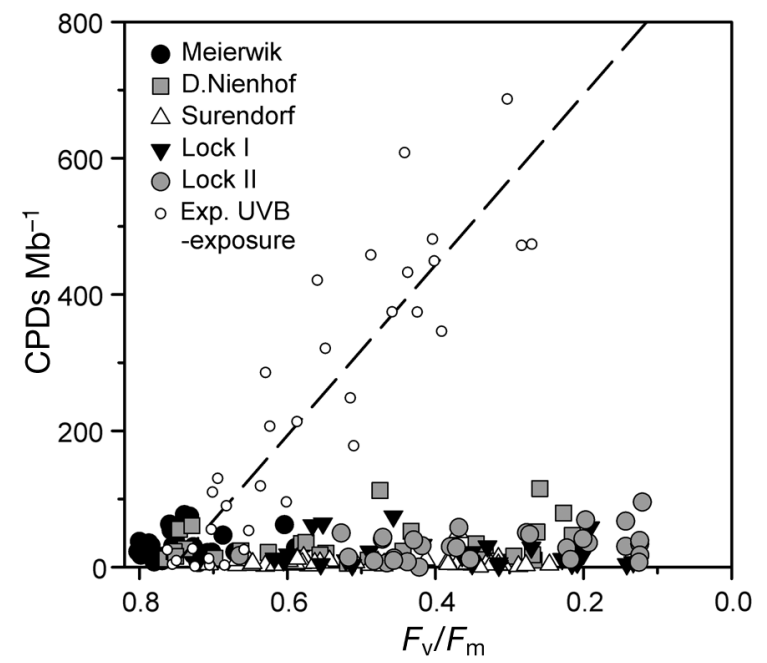

Fig. 7. Relationship between cyclobutane-pyrimidine dimers per megabase (CPDs $\mathrm{Mb}^{-1}$ ) and optimal quantum yield $\left(F_{\mathrm{v}} / F_{\mathrm{m}}\right)$ determined in parallel samples in Ulva intestinalis. Data points are from diel courses shown in Figs. 2 and 5 or from experimental (Exp.) exposure to UVB irradiation alone in the laboratory. The regression coefficient of laboratory results is $\mathrm{r}^{2}=0.82$ 


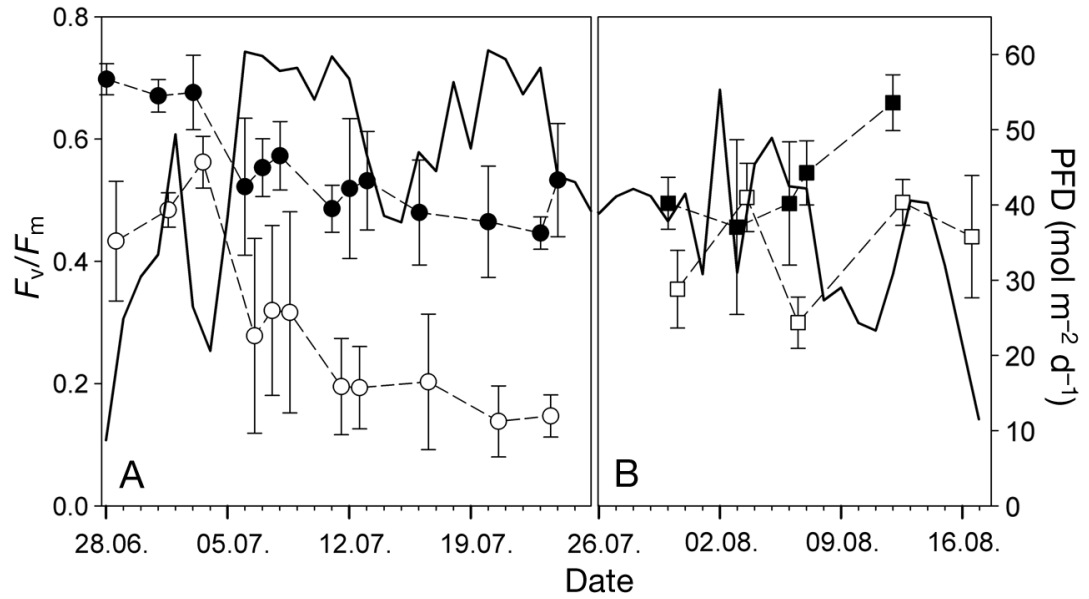

Fig. 8. Long-term observation of daily sums of photon flux density (PFD; solid line) and optimal quantum yield of photosystem II $\left(F_{\mathrm{v}} / F_{\mathrm{m}}\right)$ in $U$. intestinalis at the Lock in 2013. (A) First run; (B) second run. Data are means \pm SD, $n=4$.

Closed symbols: midnight values; open symbols: noon values

justed $\mathrm{R}^{2}$ of 0.611 for the first run of the long-term experiment (regression not shown). In the second run, no significant regression was detectable, probably due to fewer observations. However, in a combined data set of both runs, all values showed the same dependency and the regression was highly significant $\left(\mathrm{R}^{2}{ }_{\mathrm{adj}}=0.685\right.$, not shown $)$.

CPD concentrations were not correlated with the concomitant daily $\mathrm{UVB}_{\mathrm{BE}}$ doses during the first run of the longterm study $\left(\mathrm{p}=0.071, \mathrm{R}^{2}\right.$ adj $=0.243$, regression not shown; Fig. 9). In strong contrast to PSII activity, no differences of DNA damage between day and night were observed. During the first week the concentrations of CPDs were barely above the detection limit. Even on 6

lel samples (Fig. 7). It is clearly demonstrated that the 2 targets do not respond similarly, $F_{\mathrm{v}} / F_{\mathrm{m}}$ showing a much higher sensitivity towards sunlight than DNA integrity. In contrast, under experimental UVB exposure, a tight correlation of DNA lesions and optimal quantum yield was found in $U$. intestinalis (Fig. 7, open circles).

\section{Long-term study}

At the Lock, the boxes were exposed for 4 wk in July and the experiment was repeated with fresh algae for $3 \mathrm{wk}$ in August. The optimal quantum yield during these periods varied strongly (Fig. 8). In the first week of July, daily sums of PFD remained around 30 to $40 \mathrm{~mol} \mathrm{~m} \mathrm{~m}^{-2}$ and $F_{\mathrm{v}} / F_{\mathrm{m}}$ at midnight and noon stayed high (Fig. 8A). On 6 July, the daily PFD doses suddenly increased due to fine weather. During this period of high irradiance, the night and day maximum quantum yields clearly dropped. No trend of $F_{\mathrm{v}} / F_{\mathrm{m}}$ at night was found over the time span of low or high irradiance (linear regression, $\mathrm{p}=0.4165$ and $\mathrm{p}=0.1668$, data not shown). However, the absolute levels of $F_{\mathrm{v}} / F_{\mathrm{m}}$ were significantly lower during the high light period, as evidenced by different $y$-intercepts of the regression lines. The overall minimum $F_{\mathrm{v}} / F_{\mathrm{m}}$ of 0.14 was observed on 20 July at 12:00 h, coincident with the highest daily PFD dose. During the second run of the experiment, the variation of $F_{\mathrm{v}} / F_{\mathrm{m}}$ with the daily PFD doses was similar (Fig. 8B). Here, linear regression analysis identified a significant dependence of the $F_{\mathrm{v}} / F_{\mathrm{m}}$ noon level on the accumulated PFD dose (integrating PFD values before 13:00 h), with an ad-
July, when the daily UVB dose doubled, no strong increase in CPDs $\mathrm{Mb}^{-1}$ occurred. DNA damage was not determined during the second run of the experiment.

\section{DISCUSSION}

\section{Accumulation of CPDs under strong sunlight was lacking}

For the first time, the concentration of DNA damage and the course of the optimal quantum yield of PSII in an intertidal macroalga were simultaneously investigated in the field over a long period and with a partially high temporal resolution. Three diel courses

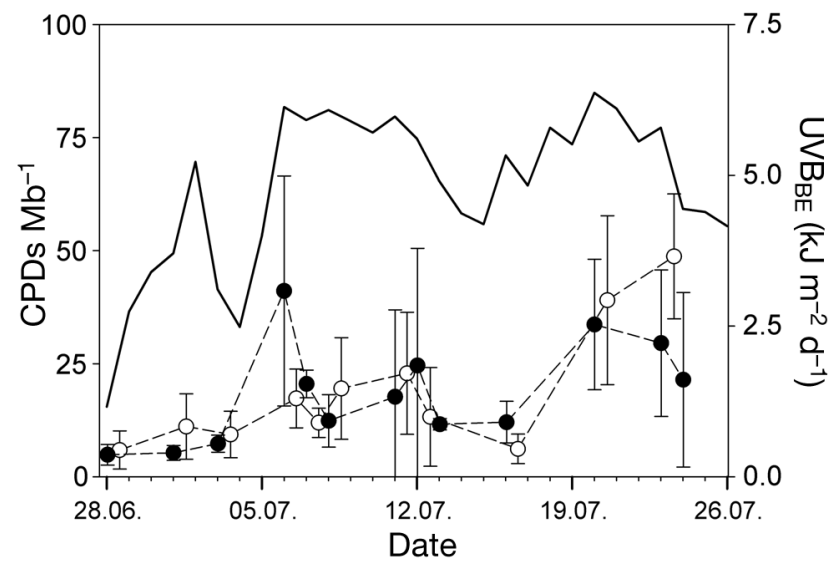

Fig. 9. Long-term observation of daily sums of biologically effective UVB irradiance ( $\mathrm{UVB}_{\mathrm{BE}}$, solid line) and cyclobutane-pyrimidine dimers per megabase (CPDs $\mathrm{Mb}^{-1}$ ) in Ulva intestinalis from the first run at the Lock. Data are means \pm $\mathrm{SD}, \mathrm{n}=4$. Closed symbols: midnight values; open symbols: noon values 
were measured in situ at the natural growth site of Ulva intestinalis. In a long-term study, we were able to keep the algae in open boxes in nearly undisturbed natural conditions with respect to the main abiotic parameters light, temperature, nutrient supply and salinity. The conditions in the boxes deviated from that naturally experienced by the algae only in one aspect. Inside the boxes, the water movement was strongly reduced, which inhibited mixing of the thalli, normally leading to shifting irradiation of a single thallus. However, U. intestinalis can also naturally be found steadily floating on the water surface, as was the case during the measuring period at Surendorf. On that day the weather conditions were such that the water surface was very calm and the thalli were not mixed by waves over the whole day. Thus, the light absorption of the thalli was extremely high on this day, as was the case during the entire long-term study.

Most of the time during the investigation period the sky was clear and daily sums of PAR and UVB radiation reached values well above $50 \mathrm{~mol} \mathrm{~m}^{-2} \mathrm{~d}^{-1}$ and $5 \mathrm{~kJ} \mathrm{~m}^{-2} \mathrm{~d}^{-1}$, respectively. Unexpectedly, in spite of this strong irradiation, probably the maximum achievable in this habitat, we observed very low concentrations of CPDs in U. intestinalis. There was no correlation of DNA damage with UVB radiation, neither on diel nor on long-term scales (Figs. $5 \& 9$, Table 2). This indicates that $U$. intestinalis did not accumulate relevant concentrations of CPDs over our study period of more than 1 mo and points to a minor influence of UVB radiation on long-term DNA integrity of $U$. intestinalis under field conditions. Similarly low CPD concentrations were described in the green macrophyte Prasiola stipitata in Antarctica (Lud et al. 2001). Likewise, there was only a very weak correlation of CPDs and UVB dose under ambient UVB conditions, which was stronger under artificial UVB enhancement. However, and in contrast to $U$. intestinalis, the genus Prasiola is known to contain UV-absorbing mycosporine-like amino acids (Karsten et al. 2005). The UVB resistance of the DNA in $U$. intestinalis is also quite remarkable if compared with that of higher plant leaves. For example, in maize, rice and Gunnera magellanica, significant levels of CPDs were induced depending on time of day or cumulative UVB dose, respectively, (Stapleton et al. 1997, Kang et al. 1998, Rousseaux et al. 1999). We also expected to occur in $U$. intestinalis, particularly because higher plants are usually well protected by screening compounds.

The obvious discrepancy between the lack of UVBscreening pigments and the absence of DNA damage
(Figs. $5 \& 6$ ) in such a high-light habitat raises the question of photoprotective mechanisms alternative to screening pigments. Such mechanisms might be especially efficient in terms of photoreactivation of DNA. However, photoreactivation is poorly investigated in green macroalgae and, so far, has been reported to be relatively inefficient compared with other macrophytes or higher plants (Takeuchi et al. 1996, van de Poll et al. 2002, Pescheck et al. 2014). Nevertheless, there are 2 important considerations that let us assume that photoreactivation may have been very efficient in $U$. intestinalis under natural sunlight conditions. Firstly, photoreactivation rates are always higher in plants acclimated to natural sunlight compared with culture-grown individuals (Takayanagi et al. 1994, Kang et al. 1998). It was shown that the expression of the photolyase is upregulated with a strong light dependence in Arabidopsis thaliana (Li et al. 2015). A similar acclimation potential of photolyase expression might exist in $U$. intestinalis as a 10 times increased photoreactivation rate was observed in freshly collected compared with low-light acclimated thalli (F. Pescheck unpubl. results). To our knowledge, investigations of the acclimation of photolyase activity are lacking for macroalgae. Secondly, irradiation with sufficient UVA radiation or blue light concomitant with the UVB exposure is obligatory for the activity of photolyase in higher plants (Takeuchi et al. 1996, Dany et al. 2001). In our experiments under artificial UVB exposure, only very low UVA radiation was present, whereas in sunlight the natural ratio of UVA:UVB existed. So far, regarding macroalgae, only for Palmaria palmata has a reduced accumulation of CPDs under simultaneous photoreactivation light been shown (Pakker et al. 2000). Therefore, we assume that one reason for the non-significant levels of CPDs we measured under strong solar irradiation may have been photoreactivation, which was highly efficient due to both induction of high photolyase activity and the presence of sufficient radiation at the appropriate wavelengths.

An additional mechanism contributing to the lack of DNA damage may be the shielding of the DNA by the chloroplasts. The concept of 'chloroplast shielding' was first described for arctic diatoms (Karentz et al. 1991). In each Ulva cell, one large cup-shaped chloroplast is located at the periphery of the cytoplasm, which during illumination orientates towards the outer surface of the thallus and thus might shade the nucleus efficiently from radiation (Britz et al. 1976). In U. clathrata this effect is suggested to increase the UVB resistance of the DNA by $50 \%$ in 
comparison to Rhizoclonium riparium, a multinucleated siphonocladal species with a net-like chloroplast structure (Pescheck et al. 2014). One can speculate that the maintenance of gene expression and DNA replication is of major importance in a growing organism or in reproductive tissues, making the sacrifice of chloroplasts a reasonable strategy. In photolyase-deficient mutants of Synechocystis, the loss of PSII activity was significantly increased and the recovery significantly delayed after UVB exposure (Vass et al. 2013). This means that prevention of nuclear DNA damage would also be beneficial for repair processes in photosynthesis.

\section{Fast reversible variations of PSII efficiency indicate high potential for photoprotection}

In contrast to the observed integrity of the DNA, a strong reduction of optimal quantum yield of PSII was found in situ (Figs. 2 \& 8). However, it is not clear to what extent the observed changes in $F_{\mathrm{v}} / F_{\mathrm{m}}$ were due to photodamage or photoprotection. Both processes are a 'function of PFD ..., duration of exposure, and spectral quality' (Henley 1993) and occur simultaneously during the day in Ulva rotundata (Henley et al. 1992). During the diel cycles (Fig. 2) and the long-term study (Fig. 8, open symbols), $F_{\mathrm{v}} / F_{\mathrm{m}}$ was considerably reduced around noon, but a large portion of this reduction was reversible within a few hours (Figs. $2 \& 3$ ). This recovery had already begun while irradiances were still oversaturating (Fig. 2), which was also observed in the field study of Henley et al. (1992). The apparent absence of a pronounced hysteresis (Fig. 3) suggests either the presence of protective downregulation or a very rapid repair cycle (Allakhverdiev \& Murata 2004). A fast repair capacity of PSII was found in a laboratory study of the closely related species $U$. clathrata, reaching $50 \%$ repair within $3 \mathrm{~h}$ of a strong UVB challenge (Pescheck et al. 2014). Therefore, it is possible that repair rates in $U$. intestinalis were able to compensate for the induction of protein damage.

However, recovery during the evenings was not fully complete until darkness set in (Figs. 2 \& 8). In some diel time courses, a further increase in $F_{\mathrm{v}} / F_{\mathrm{m}}$ was observed during the early morning hours when the sun rose and irradiation potentially enabled additional recovery (Allakhverdiev \& Murata 2004). The divergence of the optimal quantum yield at night from the empirical maximum (close to 0.8 in U. rotundata [Henley et al. 1992], and 0.75 as the overall average of $U$. intestinalis in the present study) may be considered as chronic damage to PSII. In the longterm course of the midnight values a sudden decrease in $F_{\mathrm{v}} / F_{\mathrm{m}}$ was observed upon the change from cloudy to bright weather conditions, but during the high light period no further significant drop was detected by a regression line analysis (Fig. 8, closed symbols). It appears that during the bright weather period a new, more or less stable balance between damage and repair was established. Because this balance was already achieved in the first days of high light stress, apparently no further acclimation took place. In another Ulva species, Ulva rigida, it took more than $7 \mathrm{~d}$ to reach constant growth under full sunlight after transfer of the thalli from their natural site (Altamirano et al. 2000). Reduced growth in that study was accompanied by an increase in heat dissipation of PSII (NPQ), which rose over the study period of $20 \mathrm{~d}$. Other species of Ulva, such as $U$. rotundata, also increase their dissipation capacity when acclimated to strong light (Osmond et al. 1993). Thus, the constantly reduced quantum yield we measured under long-term high-light conditions might have been caused by the development of a longer lasting NPQ, i.e. a sustained downregulation of PSII quantum efficiency.

Support for the presence of a high downregulation of PSII comes from the observation of a strong decrease of the basal fluorescence $\left(F_{0}\right)$ during the diel courses (Fig. 4). As described above, in Ulva, the chloroplasts do not move to the sides of the cells in high light but orient themselves parallel to the outer thallus surface. Hence, the lowering of $F_{\mathrm{o}}$ is probably not due to chloroplast movements but must be ascribed to the development of a substantial NPQ of $F_{\mathrm{o}}$ (Franklin et al. 1992). The in situ $F_{\mathrm{o}}$-quench during the exposure to sunlight may have been even stronger than we detected, as a significant dark period (of 15 or $20 \mathrm{~min}$ ) was applied before fluorescence was measured (Fig. 4, open symbols). At noon, $F_{\mathrm{o}}$ was decreased compared with the morning level even after 60 min dark adaptation (Fig. 4, closed symbols). Interestingly, the reversibility of the $F_{0^{-}}$ quench was much slower at the Lock than in Surendorf. While the algae in Surendorf received relatively little sunlight during the preceding week, the algae were strongly exposed for at least $1 \mathrm{wk}$ at the Lock. Hence, the different kinetics of $F_{o}$ quenching could be an indication of a long-term acclimation to high irradiance. Similarly, Henley et al. (1992) observed a clear $F_{\mathrm{o}}$-quench in $U$. rotundata acclimated to full sunlight in contrast to algae acclimated to only $9 \%$ of sunlight. The quenching in $U$. intestinalis, which was much stronger than that usually observed in higher 
plants, indicated an intense NPQ and might have been associated with zeaxanthin formation. It is known that in higher plants under light stress conditions, a higher amount of zeaxanthin is retained overnight in the chloroplasts to facilitate NPQ (Barker et al. 2002). Conclusively, photoprotective downregulation of PSII quantum yield seems as powerful in $U$. intestinalis as in $U$. rotundata (Henley et al. 1992). Notably, irrespective of the underlying mechanism that caused the quenching, the chlorophyll fluorescence data in total show that a strong high light stress was acting on the sampled thalli.

\section{Relative sensitivity of DNA integrity and PSII}

The parallel analysis of 2 major photosensitive components in the present study enabled us to investigate their relative sensitivity in situ (Fig. 7). Moreover, comparing these in situ data with laboratory results helps to evaluate the relative sensitivities of both targets. In laboratory experiments, the same UVB dose generated from fluorescence tubes caused significantly more CPDs than in situ (Fig. 6). Our data suggest that, due to the mitigating effect of UVA radiation in sunlight, the balance of CPD induction and photoreactivation is shifted towards the latter under natural sunlight compared with the experimental UVB exposure. Clearly, exposure to natural sunlight is necessary to be able to judge the ecological impact of UVB on DNA integrity and PSII function. In contrast to DNA integrity, it seems that PSII function is not similarly favored by solar irradiation, especially in the long-term comparison where PSII function was lowered under high solar irradiances, whereas DNA integrity was unaffected. This means that both targets displayed different long-term responses. Avoidance of long-term accumulation of DNA damage might be an important ecological advantage of $U$. intestinalis to gain dominance in the intertidal. Cellular tolerance processes as the repair cycle of PSII rely on the continuous availability of intact transcription. It was shown that unrepaired DNA damage can reduce the UVB tolerance of a cyanobacterium (Vass et al. 2013). The observed different sensitivity of PSII and the DNA in Ulva is in agreement with results from dinoflagellates, where photoinhibition dominated over DNA damage under natural sunlight (Helbling et al. 2008). However, the observed reduction of PSII function may not be problematic for $U$. intestinalis in its natural high-light habitat. Under oversaturating irradiances, as were observed at noon, this reduction does not necessarily lower the maximal photosynthesis rate and therefore would not inhibit growth (Henley 1993). To conclude, in contrast to expectations based on laboratory studies, $U$. intestinalis proved to be a very high-light-tolerant species.

Acknowledgements. During the fieldwork, Nele Hein, Cayssa Staggen, Christine Bönniger, Hanna Jähmlich, Paul Wieners and Jens Hermann lent many helping hands. Dr. Florian Weinberger gave useful advice for the conduct of the long-term experiment. Many thanks to Susanne Wolf for help with DNA extraction and blotting. Prof. H. Brendelberger generously loaned us several life jackets. Prof. K. Krupinska is thanked for the use of a photo laboratory. Sincere thanks are due to Mr. H. Koch of the Waterways and Shipping office in Kiel Holtenau for support and the generous permission to access the lock area in Kiel Holtenau. The improvement of the manuscript by the comments of 2 anonymous reviewers is gratefully acknowledged.

\section{LITERATURE CITED}

Allakhverdiev SI, Murata N (2004) Environmental stress inhibits the synthesis de novo of proteins involved in the photodamage-repair cycle of photosystem II in Synechocystis sp. PCC 6803. Biochim Biophys Acta Bioenerg 1657:23-32

Altamirano M, Flores-Moya A, Figueroa FL (2000) Longterm effects of natural sunlight under various ultraviolet radiation conditions on growth and photosynthesis of intertidal Ulva rigida (Chlorophyceae) cultivated in situ. Bot Mar 43:119-126

Barker DH, Adams WW, Demmig-Adams B, Logan BA, Verhoeven AS, Smith SD (2002) Nocturnally retained zeaxanthin does not remain engaged in a state primed for energy dissipation during the summer in two yucca species growing in the Mojave Desert. Plant Cell Environ 25: 95-103

Bischof K, Hanelt D, Aguilera J, Karsten U, Vogele B, Sawall T, Wiencke C (2002) Seasonal variation in ecophysiological patterns in macroalgae from an Arctic fjord. I. Sensitivity of photosynthesis to ultraviolet radiation. Mar Biol 140:1097-1106

Bornman JF, Reuber S, Cen YP, Weissenböck G (1997) Ultraviolet radiation as a stress factor and the role of protective pigments. In: Lumsden P (ed) Plants and UV-B: responses to environmental change. Cambridge University Press, Cambridge, p 157-168

Bray CM, West CE (2005) DNA repair mechanisms in plants: crucial sensors and effectors for the maintenance of genome integrity. New Phytol 168:511-528

Britt AB (1996) DNA damage and repair in plants. Annu Rev Plant Physiol Plant Mol Biol 47:75-100

Britz SJ, Pfau J, Nultsch W, Briggs WR (1976) Automatic monitoring of a circadian rhythm of change in light transmittance in Ulva. Plant Physiol 58:17-21

Buma AGJ, Helbling EW, de Boer MK, Villafañe VE (2001) Patterns of DNA damage and photoinhibition in temperate South-Atlantic picophytoplankton exposed to solar ultraviolet radiation. J Photochem Photobiol B 62:9-18

Cadet J, Mouret S, Ravanat JL, Douki T (2012) Photoinduced damage to cellular DNA: direct and photosensitized reactions. Photochem Photobiol 88:1048-1065 
Caldwell MM, Bornman JF, Ballare CL, Flint SD, Kulandaivelu G (2007) Terrestrial ecosystems, increased solar ultraviolet radiation, and interactions with other climate change factors. Photochem Photobiol Sci 6:252-266

> Dany AL, Douki T, Triantaphylides C, Cadet J (2001) Repair of the main UV-induced thymine dimeric lesions within Arabidopsis thaliana DNA: evidence for the major involvement of photoreactivation pathways. J Photochem Photobiol B 65:127-135

$>$ Douki T, Court M, Sauvaigo S, Odin F, Cadet J (2000) Formation of the main UV-induced thymine dimeric lesions within isolated and cellular DNA as measured by high performance liquid chromatography-tandem mass spectrometry. J Biol Chem 275:11678-11685

> Figueroa FL, Nygård C, Ekelund N, Gómez I (2003) Photobiological characteristics and photosynthetic UV responses in two Ulva species (Chlorophyta) from southern Spain. J Photochem Photobiol B 72:35-44

Franklin LA, Levavasseur G, Osmond CB, Henle WJ, Ramus $\mathrm{J}$ (1992) Two components of onset and recovery during photoinhibition of Ulva rotundata. Planta 186:399-408

> Ghetti F, Herrmann H, Häder DP, Seidlitz HK (1999) Spectral dependence of the inhibition of photosynthesis under simulated global radiation in the unicellular green alga Dunaliella salina. J Photochem Photobiol B 48:166-173

Gómez I, Lopez-Figueroa F, Ulloa N, Morales V, Lovengreen C, Huovinen P, Hess S (2004) Patterns of photosynthesis in 18 species of intertidal macroalgae from southern Chile. Mar Ecol Prog Ser 270:103-116

Hakala M, Tuominen I, Keranen M, Tyystjärvi T, Tyystjärvi E (2005) Evidence for the role of the oxygen-evolving manganese complex in photoinhibition of photosystem II. Biochim Biophys Acta Bioenerg 1706:68-80

Hakala-Yatkin M, Sarvikas P, Paturi P, Mäntysaari M and others (2011) Magnetic field protects plants against high light by slowing down production of singlet oxygen. Physiol Plant 142:26-34

> Helbling EW, Buma AGJ, van de Poll W, Fernández Zenoff MV, Villafañe VE (2008) UVR-induced photosynthetic inhibition dominates over DNA damage in marine dinoflagellates exposed to fluctuating solar radiation regimes. J Exp Mar Biol Ecol 365:96-102

> Henley W (1993) Measurement and interpretation of photosynthetic light-response curves in algae in the context of photoinhibtion and diel changes. J Phycol 29:729-739

> Henley WJ, Lindley ST, Levavasseur G, Osmond CB, Ramus J (1992) Photosynthetic response of Ulva rotundata to light and temperature during emersion on an intertidal sand flat. Oecologia 89:516-523

> Jahns P, Holzwarth AR (2012) The role of the xanthophyll cycle and of lutein in photoprotection of photosystem II. Biochim Biophys Acta Bioenerg 1817:182-193

> Jansen MAK, Bornman JF (2012) UV-B radiation: from generic stressor to specific regulator. Physiol Plant 145:501-504

> Jansen MAK, Gaba V, Greenberg BM (1998) Higher plants and UV-B radiation: balancing damage, repair and acclimation. Trends Plant Sci 3:131-135

> Jegerschöld C, Virgin I, Styring S (1990) Light-dependent degradation of the D1 protein in photosystem II is accelerated after inhibition of the water splitting reaction. Biochemistry 29:6179-6186

Kang HS, Hidema J, Kumagai T (1998) Effects of light environment during culture on UV-induced cyclobutyl pyrimidine dimers and their photorepair in rice (Oryza sativa L.). Photochem Photobiol 68:71-77
Karentz D, Cleaver JE, Mitchell DL (1991) Cell-survival characteristics and molecular responses of Antarctic phytoplankton to ultraviolet-B radiation. J Phycol 27: 326-341

Karsten U, Friedl T, Schumann R, Hoyer K, Lembcke S (2005) Mycosporine-like amino acids and phylogenies in green algae: Prasiola and its relatives from the Trebouxiophyceae (Chlorophyta). J Phycol 41:557-566

Koeman RPT, van den Hoek C (1982) The taxonomy of Enteromorpha Link, 1820, (Chlorophyceae) in the Netherlands. I. The section Enteromorpha. Arch Hydrobiol Suppl Algol Stud 32:279-330

Li N, Teranishi M, Yamaguchi H, Matsushita T and others (2015) UV-B-induced CPD photolyase gene expression is regulated by UVR8-dependent and -independent pathways in Arabidopsis. Plant Cell Physiol 56: 2014-2023

> Lud D, Buma AGJ, van de Poll WH, Moerdijk TC, Huiskes AHL (2001) DNA damage and photosynthetic performance in the Antarctic terrestrial alga Prasiola crispa ssp. antarctica (Chlorophyta) under manipulated UV-B radiation. J Phycol 37:459-467

- Michler T, Aguilera J, Hanelt D, Bischof K, Wiencke C (2002) Long-term effects of ultraviolet radiation on growth and photosynthetic performance of polar and cold-temperate macroalgae. Mar Biol 140:1117-1127

- Mitchell DL, Nairn RS (1989) The biology of the (6-4) photoproduct. Photochem Photobiol 49:805-819

Müller P, Li XP, Niyogi KK (2001) Non-photochemical quenching. A response to excess light energy. Plant Physiol 125:1558-1566

Nelson TA, Nelson AV, Tjoelker M (2003) Seasonal and spatial patterns of 'green tides' (ulvoid algal blooms) and related water quality parameters in the coastal waters of Washington State, USA. Bot Mar 46:263-275

- Nishiyama Y, Yamamoto H, Allakhverdiev SI, Inaba M, Yokota A, Murata N (2001) Oxidative stress inhibits the repair of photodamage to the photosynthetic machinery. EMBO J 20:5587-5594

> Ohnishi N, Allakhverdiev SI, Takahashi S, Higashi S, Watanabe M, Nishiyama Y, Murata N (2005) Two-step mechanism of photodamage to photosystem II: step 1 occurs at the oxygen-evolving complex and step 2 occurs at the photochemical reaction center. Biochemistry 44 : 8494-8499

> Osmond CB, Ramus J, Levavasseur G, Franklin LA, Henley WJ (1993) Fluorescence quenching during photosynthesis and photoinhibition of Ulva rotundata Blid. Planta 190:97-106

> Pakker H, Martins RST, Boelen P, Breeman AGJ (2000) Effects of temperature on the photoreactivation of ultraviolet-B-induced DNA damage in Palmaria palmata (Rhodophyta). J Phycol 36:334-341

Peak M, Peak J (1983) Use of action spectra for identifying molecular targets and mechanisms. Physiol Plant 58: 367-372

> Pescheck F, Bischof K, Bilger W (2010) Screening of ultraviolet-A and ultraviolet-B radiation in marine green macroalgae (Chlorophyta). J Phycol 46:444-455

> Pescheck F, Lohbeck KT, Roleda MY, Bilger W (2014) UVBinduced DNA and photosystem II damage in two intertidal green macroalgae: distinct survival strategies in UV-screening and non-screening Chlorophyta. J Photochem Photobiol B 132:85-93

> Reed R, Russell G (1979) Adaptation to salinity stress in pop- 
ulations of Enteromorpha intestinalis (L) Link. Estuar Coast Mar Sci 8:251-258

Roleda MY, Wiencke C, Hanelt D (2006) Thallus morphology and optical characteristics affect growth and DNA damage by UV radiation in juvenile Arctic Laminaria sporophytes. Planta 223:407-417

Rousseaux MC, Ballaré CL, Giordano CV, Scopel AL and others (1999) Ozone depletion and UVB radiation: impact on plant DNA damage in southern South America. Proc Natl Acad Sci USA 96:15310-15315

Rozema J, Boelen P, Solheim B, Zielke M, and others (2006) Stratospheric ozone depletion: high arctic tundra plant growth on Svalbard is not affected by enhanced UV-B after 7 years of UV-B supplementation in the field. Plant Ecol 182:121-135

Sancar A (2003) Structure and function of DNA photolyase and cryptochrome blue-light photoreceptors. Chem Rev 103:2203-2237

Sauerbier W, Millette RL, Hackett PB Jr (1970) The effects of ultraviolet irradiation on the transcription of T4 DNA. Biochim Biophys Acta Nucleic Acids Protein Synth 209: 368-386

Setlow R, Carrier W (1966) Pyrimidine dimers in ultravioletirradiated DNAs. J Mol Biol 17:237-254

Snyrychova I, Kos PB, Hideg É (2007) Hydroxyl radicals are not the protagonists of UV-B-induced damage in isolated thylakoid membranes. Funct Plant Biol 34: 1112-1121

Sousa W (1979) Experimental investigations of disturbance and ecological succession in a rocky inter-tidal algal community. Ecol Monogr 49:227-254

Stapleton AE, Thornber CS, Walbot V (1997) UV-B component of sunlight causes measurable damage in fieldgrown maize (Zea mays L): developmental and cellular heterogeneity of damage and repair. Plant Cell Environ 20:279-290

Takahashi S, Milward SE, Yamori W, Evans JR, Hillier W, Badger MR (2010) The solar action spectrum of photosystem II damage. Plant Physiol 153:988-993

Takayanagi S, Trunk J, Sutherland J, Sutherland B (1994) Alfalfa seedlings grown outdoors are more resistant to UV-induced DNA damage than plants grown in a UVfree environmental chamber. Photochem Photobiol 60: 363-367

Takeuchi Y, Murakami M, Nakajima N, Kondo N, Nikaido O (1996) Induction and repair of damage to DNA in

Editorial responsibility: Morten Pedersen,

Roskilde, Denmark cucumber cotyledons irradiated with UV-B. Plant Cell Physiol 37:181-187

Teramura AH, Sullivan JH (1994) Effects of UV-B radiation on photosynthesis and growth of terrestrial plants. Photosynth Res 39:463-473

Turnbull JD, Robinson SA (2009) Accumulation of DNA damage in Antarctic mosses: correlations with ultraviolet-B radiation, temperature and turf water content vary among species. Glob Change Biol 15:319-329

> Valladares F, Pearcy RW (1997) Interactions between water stress, sun-shade acclimation, heat tolerance and photoinhibition in the sclerophyll Heteromeles arbutifolia. Plant Cell Environ 20:25-36

van de Poll WH, Eggert A, Buma AGJ, Breeman AM (2001) Effects of UV-B-induced DNA damage and photoinhibition on growth of temperate marine red macrophytes: Habitat-related differences in UV-B tolerance. J Phycol 37:30-37

van de Poll WH, Hanelt D, Hoyer K, Buma AGJ, Breeman AM (2002) Ultraviolet-B-induced cyclobutane-pyrimidine dimer formation and repair in Arctic marine macrophytes. Photochem Photobiol 76:493-500

Vass I (2012) Molecular mechanisms of photodamage in the photosystem II complex. Biochim Biophys Acta Bioenerg 1817:209-217

Vass I, Sass L, Spetea C, Bakou A, Ghanotakis DF, Petrouleas V (1996) UV-B-induced inhibition of photosystem II electron transport studied by EPR and chlorophyll fluorescence. Impairment of donor and acceptor side components. Biochemistry 35:8964-8973

Vass IZ, Kos PB, Sass L, Nagy CI, Vass I (2013) The ability of cyanobacterial cells to restore UV-B radiation induced damage to photosystem II is influenced by photolyase dependent DNA repair. Photochem Photobiol 89:384-390

Veit M, Bilger W, Mühlbauer T, Brummet W, Winter K (1996) Diurnal changes in flavonoids. J Plant Physiol 148: 478-482

Wang Y, Wang Y, Zhu L, Zhou B, Tang X (2012) Comparative studies on the ecophysiological differences of two green tide macroalgae under controlled laboratory conditions. PLOS ONE 7:e38245

> Wichard T, Charrier B, Mineur F, Bothwell JH, De Clerck O, Coates JC (2015) The green seaweed Ulva: a model system to study morphogenesis. Front Plant Sci 6:72

Submitted: December 8, 2015; Accepted: June 13, 2016

Proofs received from author(s): August 1, 2016 